\title{
Basic Principles for the Effective Use of Legal Tech Tools
}

Tomasz Zalewski

\section{Introduction}

The use of technology in the provision of legal services is not a new topic. The use of technology in legal services (LegalTech) have begun with the spread of computers and software. As early as in the 1970s, there were attempts to use computers for, among other things, analysing case law, calculating taxes, gathering evidence in court proceedings or preparing documents ${ }^{1}$.

In the US, the International Legal Technology Association ${ }^{2}$ (ILTA) was founded in 1980 to address the use of technology by lawyers. It currently has 1358 members, mainly law firms ${ }^{3}$.

A turning point in the development of LegalTech was the appearance of the first IBM PCs ${ }^{4}$ on the market in 1981. Along with them, dedicated office software also appeared on the market. In 1990, such computers were used by $59 \%$ of small law firms in the US, and in 1995, already by $87 \%$ of such firms ${ }^{5}$. Another turning point was the emergence of the Internet and the spread of e-mail.

Such processes have been taking place all over the world. Law firms began to use IT tools as standard in their operations and this continues to this day. The market of software producers responded to the law firms' interest in IT tools by starting to develop specialised programmes intended only for lawyers, such as law firm management software. Publishers of legal publications have also begun to prepare their legal information databases in electronic form.

1 Robert P. Bigelow, 'The Use of Computers in the Law' (1973) 24, 4 Hastings Law Journal $<$ https://repository.uchastings.edu/hastings_law_journal/vol24/iss4/4> access: 17 March 2021.

$2<$ https://www.iltanet.org/home?ssopc=1> accessed 17 March 2021.

$3<$ https://www.iltanet.org/about $>$ accessed 17 March2021.

4 Robert Ambrogi, 'A Chronology of Legal Technology 1842-1995'<https://www.l awsitesblog.com/2010/02/chronology-of-legal-technology-1842.html> access 17 March 2021.

5 ibid. 
As a result, the market for LegalTech tools emerged. However, it initially developed mainly in the US and the UK - countries with the largest law firms forming the market for such solutions. In other countries the offer was much more modest. It was not until the development of cloud computing technology, enabling access to many solutions that previously required one's own server infrastructure, that the LegalTech market really took off almost worldwide. Today, estimates of the number of companies that develop LegalTech tools range from $1200^{6}$ to over $5000^{7}$.

More and more financial investors are interested in ventures in the LegalTech industry. There are many such investments and their scale ${ }^{8}$ is increasing. Financial investments in the development of technologies for the legal services industry should therefore soon result in more LegalTech solutions.

However, to date, the vast majority of IT tools used by law firms are primarily a package of standard office software in the form of programs for preparing documents and sending them by e-mail. It is usually enriched by an electronic legal information database, typically accessible via the Internet, and, in the case of law firms with at least a few staff, a law firm management program. These are tools that should be classified as LegalTech 1.0, i.e. technology supporting the activity of lawyers as professionals. The catalogue of such tools is subject to change all the time, as market offerings change, and also in result of influence of external factors such as the COVID-19 pandemic, which has brought into widespread use a number of online services for remote working, such as videoconferencing.

However, all these tools are mainly used in a traditional way, i.e. they do not fundamentally change the operating model of lawyers and their law firms. These tools allow the implementation of the same business processes that were carried out without their use, only in a digitalised form.

\section{Examples of Typical LegalTech 1.0 Products and Services}

Most law firms use typical IT solutions that are not particularly different from those used by other businesses, regardless of their industry. These are

$6<$ https://www.crunchbase.com/hub/legal-tech-companies> accessed 17 March 2021.

7 <https://www.legalpioneer.org/> accessed 17 March 2021.

8 Robert Ambrogi, 'At \$1.2 Billion, 2019 Is A Record Year for Legal Tech Investments - And It's Only September' <https://www.lawsitesblog.com/2019/09/at-1-1-bi llion-2019-is-a-record-year-for-legal-tech-investments-and-its-only-september.html> access: 17 March 2021; 
solutions enabling the production of documents in electronic form (office suite), their storage and management (computer disk, server), printing and copying and electronic communication (e-mail).

Producers of LegalTech solutions offer additional tools to this set, specific to the legal services sector ${ }^{9}$. These may include:

1) law firm or legal department management software - allows for efficient organisation of work on individual client cases, especially in a team of several people;

2) time recording programmes for lawyers - allow time to be recorded and allocated to individual cases and clients, which facilitates billing to clients;

3) virtual data rooms - allow a set of documents for analysis to be placed on a server that can be accessed by the buyer's legal advisors, thus allowing the legal due diligence review of the company to be organised efficiently during the transaction;

4) software for patent attorneys - facilitates the management of industrial property rights by, for example, reminding of any renewal deadlines or faster verification of registrability.

\section{What Is LegalTech 1.0 Used For?}

Classic LegalTech tools - such as those mentioned above - are technology that supports the legal profession. It works in the background of the lawyer-client relationship, it does not change the way legal advice is performed, but only improves it, replacing traditional ways of working with use of computers, software and the Internet.

Preparing a contract using word processing software and then sending it by e-mail is simply a more convenient and faster way of editing documents and sending correspondence than handwriting or typing and sending by post. At the same time, however, it is still the same business process, only digitised.

Therefore, irrespective of the LegalTech 1.0 technological solutions used and their "modernity", legal advice is, in principle, performed in the same way as before - it is advice performed in a "craftsman" manner, where the most important thing is the work of a particular lawyer and his skills.

9 More in Part III, Chapter 4. 
LegalTech 1.0 tools are usually implemented in a way that takes into account or even directly results from external pressure. Communication by email is due to the fact that such communication is expected by clients. The presentation of budgets in spreadsheet form is most often the result of a client requirement. Therefore, the basic impetus for the implementation and use of such solutions is the digitisation of the economy, in particular the digitisation of the courts and judicial system.

LegalTech 1.0 tools are thus implemented in the rhythm of new products appearing on the market or as improved versions of these products become available, as well as in response to requirements arising from legislative changes or customer demands.

\section{How to Implement and Use LegalTech 1.0 Tools?}

Lawyers usually have no doubt that using technology brings them many benefits. In particular, they point to increased productivity and automation of repetitive tasks ${ }^{10}$.

Among LegalTech 1.0 tools, the most important are:

1) electronic document management software - the so-called DMS (Document Management System);

2) electronic legal information databases;

3) case management software - allows to create individual assignments and assign documents and correspondence to them, and to settle them.

Among these tools, it is worth noting the electronic legal information databases, which are slowly turning from ordinary databases into a comprehensive system for analysing the legal system with many additional options like facilitating the editing of documents using the content contained in the database.

Implementing LegalTech 1.0 tools, in most cases, is not fundamentally different from implementing other IT solutions. Each such implementation is a project in which technical, as well as organisational, financial and human considerations must be taken into account. The ultimate success of the implementation is influenced by all these factors.

10 See Diagnosis of lawyers' needs regarding the use of IT tools in legal services, Fundacja LegalTech Polska Politechnika Warszawska, 2018) <https://lega ltechpolska.pl/wp-content/uploads/2018/06/2018.06.25_Raport_LegalTech_ost.pd f> accessed 17 March 2021. 
The first and basic element of such a project is to define the specific problems that the tool is supposed to solve. This usually involves analysing the lawyers' current way of working and assessing the possibility of improving it by implementing a technological solution.

Many lawyers are reluctant to change their way of working. When implementing software, they want to replicate their habits, e.g. with regard to document workflows, in a digital environment. This often leads to the need to introduce many modifications to standard software, which lengthens the implementation process and increases its costs. It is also not always the best solution from the point of view of efficiency - transferring an inefficient paper document workflow procedure to an electronic form will not bring the expected benefits.

Many smaller law firms in such cases rely on software vendors who include in the standard configuration of the software the average needs of their other clients - law firms. Accepting a standard configuration may therefore not only be the simplest solution, but also an adaptation to market standards in terms of work organisation.

The best solution, however, is always to analyse organisational processes within a specific law firm, as well as to improve and simplify them before implementation, and only then to implement a technological solution that will allow, for example, more effective realisation of either entire processes or their most critical stages. This involves choosing either a comprehensive solution or a set of separate tools supporting specific activities ${ }^{11}$.

Other factors important in implementing LegalTech 1.0 tools in a law firm are proper internal communication and involvement of lawyers in the project, taking care of integration with other systems in use, and choosing the program based on defined needs.

However, implementation of such solutions is becoming increasingly easy, especially when the solution is offered in the Software as a Service (SaaS) model, which significantly reduces implementation time and usually does not require changes to the law firm's own IT infrastructure ${ }^{12}$.

11 Ryszard Sowiński, Bartłomiej Majrzak, 'Programy do zarządzania kancelarią prawną. Jak wybrać i wdrożyć najlepszy program dla Twojej kancelarii?’ <https://kirp .pl/raport-programy-do-zarzadzania-kancelaria-prawna-juz-dostepny/> accessed 17 March 2021.

12 Yara Nardi, 'Cloud computing and the use of legal technology in the cloud' (Legal Insights Europe 7 August 2020) <https://blogs.thomsonreuters.com/legal -uk/2020/08/07/cloud-computing-and-the-use-of-legal-technology-in-the-cloud/> accessed 17 March 2021. 
Finally, it is worth mentioning that many lawyers do not see the potential and all the functionalities embed in already implemented tools. This applies especially to office suites, which are currently offered in the form of SaaS and are enriched with a number of add-ons that allow for simple automation or even the creation of algorithms without the need to know programming languages (the so-called no-code technology). Therefore, it is worth taking a look at least the possibilities that are built in the office software you already own. A spreadsheet is a powerful tool that can be used in many new ways, e.g. to create a schedule of events for a court case, or to create a handy database, while a mail program has many possibilities of automating notifications, automatic replies or forwarding messages ${ }^{13}$.

The COVID-19 pandemic popularised the use of video conferencing tools, which also began to be used for training and webinars, and even for court hearings. The popularity of Microsoft Teams, initially used only for videoconferencing, has led many lawyers to discover its other capabilities and the benefits of team collaboration and communication beyond email.

\section{LegalTech 2.0 - a Breakthrough in the Way We Think}

Several years ago, it began to be recognised that technology was not only making lawyers' jobs easier, but was also enabling a shift in the way legal advice was delivered. The breakthrough in the way we think about technology in the context of legal services can be attributed to $R$. Susskind, who in 2008 published a book entitled "The end of the world of lawyers?" 14 . He indicated that the legal advice industry would be changed in the near future under the influence of two factors: the commoditisation of legal services and the development of information technology. Among the technologies that were expected to impact the legal industry, R. Susskind mentioned automation of document creation, interactive self-service systems for legal advice, and online systems for dispute resolution. It is worth noting that these predictions, as indicated, were made in 2008 and that $R$. Susskind did not take into account the rapid development of tools based on artificial intelligence. However, these predictions have proven to be accurate. Many of the current LegalTech trends fit in, although not all are yet being used on a large scale. This is facilitated by the progressive

13 See also the analysis in Part III, Chapter 4.

14 Richard Susskind, The End of Lawyers? Rethinking the Nature of Legal Services, (Oxford 2010). 
digitalisation of the economy and social life, which to some extent even makes it impossible to practise the legal profession as before.

Digitisation means for lawyers an increasing amount of data that they have to consider and analyse in order to provide legal advice. This data consists of both client data (and its quantity only increases in the age of electronic communication), as well as data in the form of judicial decisions and legal literature. These data are often so extensive that it is no longer possible to analyse them in a completely manual manner. The use of technological solutions for data analysis not only speeds up the analysis, but also enables analysis in a way that changes the quality and manner of the legal services provided. Advanced document analysis allows for the detection of many problems or issues that are impossible to spot when reviewing documents in a traditional manner. No one is able to notice, for example, small differences in standard contractual provisions, if the database contains several thousand similar contracts. It is also difficult to fully analyse the variation in jurisprudence on similar issues if thousands of rulings by courts of different instances are available.

In addition to providing information that has often been overlooked so far, these solutions also enable the omission of a number of manual and time-consuming activities performed by lawyers. For example, a lawyer can quickly obtain satisfactory results of analysing case law or collections of a large number of documents on his own, eliminating a stage of work usually performed by the youngest lawyers - the legal research and document analysis as part of transactional analyses.

As a result, LegalTech 2.0 tools can eliminate many of the repetitive tasks traditionally assigned to humans, but their impact on the way lawyers perform their work is potentially even greater in another respect.

Today, the value of a lawyer and his or her work derives (leaving aside the problem of skills or talent) both from knowledge of the law and from experience in advising on the application of the law. Experience is a special combination of knowledge of the law and the practical situations when the law is applied with a pragmatism which makes it possible to assess the risks involved in a given situation. Gaining experience takes time and is difficult to transfer. Young lawyers need a longer period of working with an experienced lawyer to acquire similar skills. For example, experience in contract negotiation requires participation in the negotiation of many contracts, observation of other negotiators, and analysis of key issues related to the execution of such contracts, which over time allows for easy identification of relevant issues based on their similarity to other contracts negotiated in the past. Experience also enables the lawyer to identify those 
provisions that are within normal industry practice and those that deviate from such standards.

Meanwhile, LegalTech 2.0 tools now make it possible to compare the contract under analysis with collections of other contracts, making it easier for a lawyer even without significant experience to assess the risks associated with specific provisions. If such an analysis is carried out taking into account the templates used by the company which is a party of the contract, contracts signed in the past and collections of similar contracts concluded by other companies, the lawyer will obtain knowledge that both speeds up his analysis and facilitates his decision as to the recommendation to the client, even if the lawyer in question has no experience in negotiating contracts of a given type or in a given sector ${ }^{15}$.

Another consequence of this use of technology to process large data sets is that the know-how contained in documents created by lawyers can be at least partially retained, even after they have left the law firm in question.

Thus, LegalTech 2.0 solutions allow not only to automate the work of lawyers, but also to accelerate the acquisition of experience and knowledge and to make better use of already generated know-how. An additional advantage of LegalTech 2.0 solutions is the adaptation of the law firm's offer to the real needs of clients. Not all cases or tasks entrusted to the law firm by clients require "tailor-made" services. Some tasks can be performed more efficiently and cheaply if the lawyer is assisted by technological tools, while some can be automated and operate only under supervision - either by the law firm or directly by the client.

\section{How to Implement and Use LegalTech 2.0 Tools?}

In case of LegalTech 1.0 tools, the goal of their implementation is to perform tasks within law firms more efficiently, faster or cheaper. Because these solutions are designed to support lawyers in their traditional, well-defined duties, lawyers usually know what kind of solution they need and how to use it.

In case of LegalTech 2.0 tools, the situation is different. These solutions introduce methods of performing certain activities or services in a comple-

15 Tim Pullan, 'Experience: the Critical Commodity in Deal Negotiation + StarStudded Careers' (Artificial Lawyer, 12 February 2021) <https://www.artificiallaw yer.com/2021/02/12/experience-the-critical-commodity-in-deal-negotiation-star-stu dded-careers/> access 17 March 2021. 
tely different way than previously adopted by law firms. Their implementation is therefore usually the result of either noticing a new product that introduces such new solutions or the effect of innovation on the part of lawyers who want to perform their services in a new way and are then looking for appropriate tools.

Lawyers and law firms wishing to introduce LegalTech 2.0 tools should therefore follow, usually simultaneously, two paths: on one hand, they should observe new products offered on the market (which - due to the above-mentioned dynamic development - offers more and more), and on the other hand, they should develop an innovative attitude, looking for new ways to use technology to provide legal advice. This is best done in parallel, as knowledge of new tools allows to see new opportunities in the provision of legal advice, while an innovative mindset allows for sometimes non-obvious applications of available tools.

LegalTech 2.0 solutions can be divided into two basic categories: tools that solve a specific problem (e.g. online contract negotiation, contract signing, document management during transactional research) and tools that lawyers can use to create their own solution.

This second category includes a range of tools that allow lawyers to design and build legal advice solutions themselves. Typically, these are applications that allow lawyers to independently implement IT projects using so-called no-code platforms, i.e. platforms that allow users to create applications without any programming knowledge. Using ready-to-use components, even people without technical knowledge can design more or less complex IT solutions and thus implement their ideas for business improvements.

There are many no-code platforms on the market that can be used by lawyers, but there are also no-code solutions dedicated only to them ${ }^{16}$. No-code solutions are usually used to build legal knowledge bases, which can be used on a self-service basis, it is also possible to prepare standard documents or contracts using them, as well as to verify whether in a given situation specific provisions of law can be applied ${ }^{17}$.

A specific type of no-code platforms are chatbots that allow information to be collected or shared using a dialogue with the user. Chatbots are

16 Adriana Peterson, 'NoCode And Lawyers' (NoCode Journal, 12 May 2020) $<$ https://www.nocodejournal.com/posts/nocode-and-lawyers $>$ accessed 17 March 2021.

17 Examples of applications built using no-code platforms include Neota Logic and Bryter, see $<$ https://www.neotalogic.com/neota-logics-client-app-gallery/; https://b ryter.io/use-cases/> accessed 17 March 2021. 
particularly useful in providing legal assistance to consumers, allowing, for example, an initial verification whether legal assistance is possible in a specific factual situation ${ }^{18}$.

Robotic Process Automation (RPA) solutions are also becoming increasingly popular. RPA is business process automation software that operates at the user interface level - it handles various programs just like humans do. RPA software makes it possible to handle repetitive actions usually performed by humans with the use of various programmes (e.g. scan a document, save it in a specific directory, send the saved file as an attachment to the addressee). Implementation of such solutions does not require modifications to the existing IT systems or reconstruction of business processes in the office, which is their significant advantage. More and more often RPA solutions are equipped with some machine learning mechanisms, which significantly broadens the scope of their application.

It is worth noting that the functionalities included in standard office software packages can also be used to create the above described no-code or RPA solutions, e.g. allowing to create surveys in which the questions asked depend on the fulfilment of certain logical conditions, e.g. answering in a specific way to previous questions or creating simple data exchange processes between applications from the office package.

Another noteworthy division of LegalTech 2.0 solutions is between tools that the law firm uses within its own organisational structure; tools that are used to provide legal assistance to the client and tools that the law firm passes on to the client for its own use.

Tools used within the firm's own organisational structure are a natural extension of LegalTech 1.0 level tools. These are solutions that support lawyers in their tasks and often have an impact on many aspects of the firm's operations, including staffing level or its structure, but from the point of view of the client of the firm they do not change much in the firm-client relationship. These tools usually lead to improvements in the speed of service delivery and often in the quality of service, which together increase client satisfaction with the law firm's services. However, it is still legal advice provided in the traditional way.

The introduction of technology solutions for the direct delivery of legal services is already a step that requires a change of habits on both the law

18 An example is the chatbot providing advice on so-called loans in Swiss francs, which won the competition for a legal chatbot organised by Fundacja LegalTech Polska, <https://legaltechpolska.pl/konkurs-na-prawniczego-chatbota-wyniki/> access 17 March 2021. 
firm and client side. These include, for example, legal project management solutions that allow progress to be monitored both on the side of the law firm and the client or other parties involved in the project. In this case, the client has to accept the new way of communication or that draft documents are submitted to him for approval on an electronic platform.

Such solutions are not always possible to implement. While in case of solutions used within the firm's own organisational structure, the problem lies in the lawyers' habits, in this case the client may often have problems with accepting the solutions proposed. An additional difficulty may also be the need to adapt a given solution to the requirements of the client's IT department, which often exclude the possibility of storing client data in third-party IT systems other than the law firm's.

The use of such solutions also creates a new level of lawyer's responsibility towards the client. Providing legal aid with the use of technological tools means the necessity to assume responsibility not only for the substantive value of the advice, but also for the risks inherent in the technology, such as the risk of violation of professional secrecy, or the risk of improper provision of legal assistance due to failure of the technology used (e.g. failure to meet a procedural deadline or a deadline agreed with the client).

Another risk is related to the use of artificial intelligence techniques and approaches in the LegalTech tools built by the law firms or proposed by them to the clients. The first EU proposal of legal regulations for artificial intelligence ${ }^{19}$ aims to regulate not only AI solutions based on machines learning but also systems using logic- and knowledge-based approaches, including expert systems, what may include the vast majority of LegalTech tools. The regulation target mainly so-called high-risk AI solutions and this category includes, among others, AI systems intended to assist a judicial authority in researching and interpreting facts and the law and in applying the law to a concrete set of facts. The production and use of AI systems, especially high-risk systems, would require meeting several compliance requirements.

The use of technological solutions for the direct provision of legal services consequently requires lawyers to take steps to review these solutions for risks, their severity and how to mitigate them ${ }^{20}$ as well as general

19 European Commission's Proposal for a Regulation laying down harmonised rules on artificial intelligence (Artificial Intelligence Act) published on 21 April 2021 (<https://digital-strategy.ec.europa.eu/en/library/proposal-regulation-laying -down-harmonised-rules-artificial-intelligence-artificial-intelligence $>$ accessed 17 March 2021).

20 More on risk assessment and management methodologies in Part V. 
regulatory compliance. The main risk is usually the threat to professional confidentiality of information.

The initiative for using such tools sometimes comes from the client and the law firm then usually starts using them, which often results in starting to use them also in other projects, including with other clients.

It is worth noting that in such a case, the law firm does not bear the risk associated with the choice and use of a given tool - the risk is borne by the client who proposes (or requires) the use of this solution for the provision of legal assistance by the law firm. This is one of the main reasons why lawyers are more likely to use solutions proposed by clients than to offer them themselves to their clients. However, even where the initiative to use the tool comes from the client, this does not relieve the lawyer of the duty to exercise care to protect professional confidentiality - therefore, even then, the lawyer should - as a minimum - analyse the risks associated with the use of the tool and inform the client about them.

The most difficult to implement LegalTech 2.0 solutions are tools designed for self-use by clients. This is a form of legal self-service using tools provided by the law firm. These may be, for example, document generators or a database of know-how allowing for quick access to legal information on a given topic. Often such tools have the character of a so-called decision tree or conversational chatbots. A significant number of solutions of this type are offered in the area of compliance consulting, e.g. for the recognition and correct classification of tax schemes or for compliance with GDPR. Such tools can be developed in-house from scratch, created on behalf of a law firm by an external software house or created using the no-code platform discussed above.

Such tools completely change the way legal advice is provided. However, it also means changing the way legal services are offered to clients. Selling such solutions is more similar to selling software than to selling legal services. It also changes the way a law firm operates - the products delivered to the client must be updated both in terms of content and technology (i.e. the software used to present content), and the law firm is also responsible for providing technical support. As a result, law firms offering such products either have to set up their own technical team to support these products or offer such solutions through specially established entities, often in joint ventures with technology providers, what brings such products closely to classic products offered on the LegalTech software market.

In this case, the above-mentioned problem of responsibility not only for the merits of the advice, but also for the risks inherent in the technology used, is particularly pronounced. Therefore, law firms offering such soluti- 
ons usually use software provided by specialised third parties who assume the technological risks or offer it through separate entities - companies owned by the law firm or the law firm together with the technology provider. As a result, a law firm implementing such solutions usually starts to operate in a kind of capital group model, in which the law firm provides traditional advisory services and offers its clients additional services in the LegalTech 2.0 model through subsidiaries.

Another important classification of LegalTech 2.0 tools is how they are produced. While LegalTech 1.0 tools are offered by software vendors or publishers, many LegalTech 2.0 tools are offered directly by or with participation of a law firm. The development of technology and the emergence of a favourable climate for innovation in legal services has led many lawyers and law firms to see an opportunity for themselves in creating LegalTech 2.0 solutions.

Law firms that have not found the solutions they need on the market have taken various actions. Some have started producing their own software solutions, others have used no-code platforms, still others have started working with external entities to jointly prepare LegalTech solutions. Incubators for LegalTech start-ups organised by law firms have also appeared on the market to support LegalTech start-ups in the development of their products $^{21}$. Many lawyers have decided to leave their careers in law firms to start LegalTech solutions ${ }^{22}$.

\section{How to Find an Area to Use LegalTech 2.0 Tools?}

The basic direction of analysis for implementing LegalTech 2.0 tools should be the possibility of introducing automation and replacing people in routine activities.

21 Mark A. Cohen, 'The Rise of Legal Tech Incubators and Why Allen \& Overy's 'Fuse' Has the Right Stuff' (Forbes 12 February 2018) <https://www.forbes.com/sit es/markcohen1/2018/02/12/the-rise-of-legal-tech-incubators-and-why-allen-overys-f use-has-the-right-stuff/\#10482014494d > accessed 17 March 2021.

22 An example is Mariana Hagstrom from Estonia, founder of Avokaado, see The Legal Technologist, 'An interview with Mariana Hagström - From Managing Partner to Legaltech Founder' (The Legal Technologist 12 August 2020) <https:// www.legaltechnologist.co.uk/an-interview-with-mariana-hagstrom-from-managin g-partner-to-legaltech-founder/> accessed 17 March 2021. 
As many studies have shown, lawyers point to a number of activities that they consider routine or administrative ${ }^{23}$. Introducing automation in these areas may be relatively easy as it should not encounter resistance even from those lawyers who are generally reluctant to change.

To this end, it is worth performing a comprehensive analysis of each stage of legal services, from acquiring a client, through providing him with advice, to issuing an invoice and receiving payment. Very often such an analysis reveals numerous possibilities of process improvement, even without the use of any technology. After the analysis, it is worth comparing the results with available IT solutions. Even for many experienced professionals, it may come as a surprise how many possibilities are in new tools and how much they can facilitate the work of lawyers.

Automation does not have to cover the entire process of providing legal assistance. The greatest potential for development lies in tools automating some elements of process, e.g. collecting information from a potential client in order to determine the type of his/her case and directing to the appropriate lawyer in the office or digitising and describing incoming correspondence.

A rewarding area of automation is management of contracts - from their creation using templates and data through their negotiation and circulation between different people to their signing and archiving. All standard business processes, such as debt collection, can also be automated. Legal consultancy of a recurrent nature may also be automated - this category includes, for example, replying to typical queries on a given subject. Using technology, these legal queries can be made more precise by specifying their scope, redirecting them to a database of previous answers and only then directing them to a lawyer if the database does not contain the right answer.

However, the automation will be successful only if the scale of the automated problem is sufficient. Automating the creation of a contract that is signed only several times a year will probably consume more time and resources than it would pay off in a few years. It is therefore necessary to select those stages of legal services which occur in almost every case, regardless of the type of matter. It is relatively easy to identify such areas in a specialist law firm which naturally deals with specialised types of cases. Technology can significantly change the service delivery model in such law firms. The same is true in legal in-house departments - which provide their in-house client with advice closely related to the specifics of the business.

23 See Diagnosis of the needs of lawyers for the use of IT tools, 10-15. 
To visualise the impact of LegalTech 2.0 tools on the provision of legal services, one only needs to look at the personal data protection advice market. To a large extent, such services are not provided by law firms, but by consulting or IT companies that create tools allowing for partial automation of many elements related to data protection compliance. Law firms dealing with debt collection have previously gone down a similar path.

Technology allows not only for improvements of the existing market for legal services. One of its benefits is also opening up entirely new markets and new clients for legal services. Online platforms connecting lawyers with clients have already begun to really shape the market for legal advice to consumers, enabling many law firms to go beyond their local territory. Consumers have also become well accustomed to the online availability of simple legal knowledge, as well as to solutions based on automation and online access.

Technology also makes it possible to realistically arm people who want to find themselves a solution to their legal problem with tools that will allow them to deal with such situations effectively. More and more solutions are emerging that allow, for example, to semi-automatically pursue claims against air carriers for flight delays, to generate an appeal against a parking ticket or to join a collective dispute. Collective disputes are also an example of cases which, without the use of even simple technologies for collective communication and data processing, would be difficult to be handled efficiently and cost-effectively.

LegalTech 2.0 has a lot of potential to really activate citizens and consumers, who will be able to exercise their rights against the state or businesses. This is also a factor of change in the legal services market, which poses new challenges for lawyers and law firms.

\section{LegalTech 2.0 and the Expectations of Lawyers and Clients}

The potential for using information technology for the delivery of legal services, and in particular the opportunities associated with automation, have been quickly recognised on the legal market.

However, often the mere awareness of the possibility of change is not enough to bring the change. Lawyers need an incentive to change. Interest in applying technological solutions in legal advice can be motivated, on one hand, by the digitalisation of public services, from the digitalisation of court proceedings to the digitalisation of public procurement, and on the other, by changing client expectations. 
Before buying a new solution, especially one that requires commitment on the client to use it, it is therefore worth asking ourselves what expectations clients have. And lawyers' clients do not always expect to be offered technological solutions. Rather, they expect effective ways to solve their legal problems. Therefore, it will be easier to implement solutions that address internal law firm processes than solutions that involve clients.

In addition, both lawyers and clients are not always prepared to use technologically advanced products. The basic expectation of a client is an easy relationship with a lawyer that does not require too much commitment or effort on his/her part. Lawyers are usually only one of the service providers to the client, so clients will not be willing to undertake an effort of getting used to a new communication system used by a law firm just because it is more modern and offers a range of new facilities. This is one of the main reasons why e-mail communication still remains the most important means of communication despite the passage of years ${ }^{24}$.

In implementing LegalTech 2.0 solutions, law firms should therefore not focus on inventing new tools to replace those currently in use. Rather, their energy should be focused on finding ways to use the tools that their clients also use as effectively as possible, and new tools should be used where existing solutions clearly fail. Automation should focus on areas that have a real mass appeal, and the primary way to increase efficiency should be through the use of electronic information flows and digitalised business processes.

This was clearly demonstrated in the subsequent months of the COVID-19 pandemic: when companies are under pressure, they opt for solutions that work here and now and are easy to implement. The greatest value in a hastily digitised world has proven to be not in specialised tools, but in versatile tools and platforms that can be easily adapted to changing needs. The COVID-19 pandemic and the digitalisation processes accelerated by it have also provided many new lessons on the effectiveness of implementing digital solutions in business organisations. It turned out that it is not enough to have the technological tools, you still need to have properly prepared data that can be processed and used within these tools. The use of videoconferencing platforms is not much different from the use of a standard teleconference if the meeting participants do not have remote access to their documents and cannot work on them together in a shared environment.

24 Number of e-mail users worldwide from 2017 to 2024, <https:/www.statista.com/ statistics/255080/number-of-e-mail-users-worldwide/> accessed 17 March 2021. 
The biggest challenge for the development of LegalTech tools in the near future will be to create a framework for collecting data that can be used to improve these tools. It is particularly clear in the case of solutions using machine learning mechanisms. This is because many LegalTech 2.0 projects using artificial intelligence stall when the data necessary to achieve a sufficient level of accuracy is missing. Producers of these solutions need real data contained in real contracts and other legal documents, which are covered by professional confidentiality duty in law firms and are relatively rare in public circulation (although the situation varies in this regard in different countries).

For many years LegalTech was reduced to the introduction of technological solutions in law firms in the form of mainly computer programs. These solutions worked within the law firms and were used for the internal needs of the lawyers. The new wave of LegalTech solutions goes beyond this pattern.

LegalTech 2.0 or LegalTech 3.0 are solutions that need data and collaboration beyond the confines of a single law firm in order to work. Especially the full use of the potential of artificial intelligence requires such an approach. The currently offered tools in the field of natural language processing using machine learning mechanisms (e.g. for due diligence) require a lot of work to "train" them and, moreover, they give good results only when applied to large sets of repetitive documents of the same type (e.g. only to lease or licence agreements).

The challenge for both producers and law firms will be to create solutions enabling collection and sharing of data to be used for e.g. setting market standards as to the content of contractual provisions or the amount of contractual penalties, while respecting the principles of professional confidentiality. Overcoming these limitations may bring a quantum leap in the number of useful tools that will allow lawyers to significantly increase the efficiency and effectiveness of their services.

\section{Unstoppable Trend}

Information technology has begun to make a real difference to the delivery of legal services in many areas. However, no breakthrough has yet been achieved. New solutions are increasingly being tested and used, but the scale of their use does not allow to speak about a radical change in the way the entire legal services market operates.

This change will occur, but its pace will be driven both by changes in the socio-economic environment, including the digitalisation of the 
economy and public life, and by advances resulting from experiments with LegalTech tools being conducted around the world.

Clients, at least for now, are not going to hire robot lawyers, but this does not mean that lawyers can afford for passive waiting for change. 